\title{
Pemasangan Paving Block Jalan Desa Mekar Jaya Kecamatan Panongan Kabupaten Tangerang
}

\author{
Hendro Widiarto ${ }^{1}$, Sukamto $^{2}$, Ika Endrawijaya ${ }^{3}$, Pribadi Asih ${ }^{4}$, Asep Samanhudi ${ }^{5}$ \\ 1,2,3,4,5,6 Politeknik Penerbangan Indonesia Curug \\ e-mail: hendro.widiarto@ppicurug.ac.id, ${ }^{1}$ sukamto@ppicurug.ac.id, \\ ${ }^{3}$ ika.endrawijaya@ppicurug.ac.id,_pribadi.asih@ppicurug.ac.id, ${ }_{2}^{5}$ asep.samanhudi@ppicurug.ac.id
}

\begin{abstract}
Abstrak
Jalan adalah akses penting bagi warga untuk beraktifitas, tetapi jalan desa masih berupa jalan tanah belum adanya perkerasan maka hal tersebut akan menjadi kendala, terutama pada saat musim hujan yang akan menyulitkan aktifitas warga. Jalan desa adalah sesuatu hal yang sangat dibutuhkan oleh warga khususnya untuk mobilitas dalam kehidupan sehari-hari. Jalan desa merupakan sarana yang sangat dibutuhkan oleh warga di Kp. Blok Benda RT.10 RW.04 Desa Mekar Jaya Kec. Panongan Tangerang Banten Oleh sebab itu, masyarakat Kp.Blok Benda Mekar Jaya menginginkan pengadaan serta pengerasan jalan segera dilaksanakan di sepanjang jalan yang termasuk pada wilayah Panongan, khususnya jalan yang dianggap rawan terjadinya kecelakaan karena jalanan desa yang licin. Melihat adanya permintaan warga yang sangat membutuhkan perkerasan (betonisasi atau pavingisasi) jalan ini.maka kami melaksanakan Tri Darma Perguruan Tinggi dimana Politeknik Penerbangan Indonesia Curug salah satu kewajiban dosen dalam melaksanakan pengabdian pada masyarakat dengan mengambil kasus
\end{abstract}

Kata Kunci : Jalan, Paving, Perkerasan.

\begin{abstract}
The road is an important access for residents to do activities, but the village road is still a dirt road, there is no pavement so this will be an obstacle, especially during the rainy season which will complicate community activities. Village roads are something that is really needed by residents, especially for mobility in daily life. The village road is a facility that is really needed by residents in Kp. Blok Benda RT.10 RW. 04 Desa Mekar Jaya Kec. Panongan Tangerang Banten Therefore, the people of Kp Blok Benda Mekar Jaya want the procurement and paving of roads to be carried out immediately along the roads belonging to the Panongan area, especially roads that are considered prone to accidents due to slippery village roads. Seeing the demand from residents who desperately need pavement (concreting or paving) this road. then we carried out the Tri Darma Perguruan Tinggi where the Indonesian Aviation Polytechnic Curug is one of the obligations of lecturers in carrying out community service by taking cases
\end{abstract}

Keywords : Road, Paving, pavement.

\section{Pendahuluan}

\subsection{Analisis Situasi}

Jalan adalah akses penting bagi warga untuk beraktifitas, tetapi jalan desa masih berupa jalan tanah belum adanya perkerasan maka hal tersebut akan menjadi kendala, terutama pada saat musim hujan yang akan menyulitkan aktifitas warga. Jalan desa adalah sesuatu hal yang sangat dibutuhkan oleh warga khususnya untuk mobilitas dalam kehidupan sehari-hari.Jalan desamerupakansarana yang sangat dibutuhkan oleh warga di Kp. Blok Benda RT.10 RW.04 Desa Mekar Jaya Kec. Panongan Tangerang Banten 
Berdasarkan permintaan yang banyak dari warga setempat, perkerasan jalan desa ini sangat dibutuhkan. Akan tetapi, perkerasan baik betonisasi maupun pavingisasi di Kp.Blok Benda Mekar Jaya sangatlah rumit dikarenakan perlu adanya ijin dari kelurahan dan kecamatan serta biaya yang diperlukan untuk membuat perkerasan jalan. Perkerasan jalan memiliki manfaat yang sangat besar bagi seluruh masyarakat khususnya dikawasan pedesaan. Banyak wilayah didaerah pedesaan yang sangat membutuhkan bantuan untuk perkerasan jalan.Dalam hal ini kami mengajukan permohonan bantuan untuk pengadaan perkerasan jalan di Kp. Blok Benda RT.10 RW. 04 Desa Mekar Jaya Kec. Panongan Tangerang Banten.

Oleh sebab itu, masyarakat Kp.Blok Benda Mekar Jaya menginginkan pengadaan serta pengerasan jalan segera dilaksanakan disepanjang jalan yang termasuk pada wilayah Panongan, khususnya jalan yang dianggap rawan terjaadinya kecelakaan karena jalanan desa yang licin. Melihat adanya permintaan warga yang sangat membutuhkan perkerasan (betonisasi atau pavingisasi) jalan ini, maka kami. dalam melaksanakan Tri Darma Perguruan Tinggi dimana Politeknik Penerbangan Indonesia Curug salah satu kewajiban dosen dalam melaksanakan pengabdian pada masyarakat dengan mengambil judul Pemasangan Paving Block Jalan Desa Di Kp. Benda RT.10 RW 04 Desa Mekar Jaya Kecamatan Panongan Kabupaten Tangerang

\subsection{Permasalahan Mitra}

Permasalahan pertama yang dialami warga Kp. Blok Benda adalah persoalan terkait dengan pavingisasi jalan guna mengurangi terjadinya kecelakaan dikarenakan jalannan yang licin khususnya waktu musim hujan, dengan perkerasan jalan ini akan memudahkan untuk aktifitas dan mobilitas warga lebih baik terutama paada musim hujan .

Dengan permasalahan yang dihadapi, maka prioritas utama yang harus dilakukan adalah sebagai berikut :

1. Memberi wawasan tentang perkerasaan jalan

2. Pelatihan untuk pemasangan dan standart jalan sesuai dengan type kendaraan yang melintas

\section{Metode}

Tahapan-tahapan pelaksanaan kegiatan pengabdiaan ini sebagai berikut:

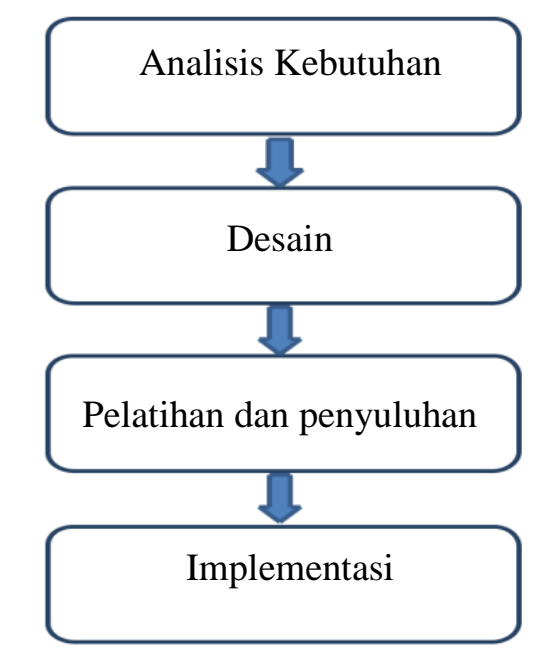

Gambar 1. Diagram alir Tahapan Kegiatan 
Dari gambar1.dapat dijelaskan Tahapan kegiatan sebagai berikut:

1. Analisa kebutuhan

a. Tahapan awal ini berupa analisis kebutuhan meliputi kebutuhan output, proses dan hasil analisa kebutuhan, dipresentasikan kepada kelompok masyarakat, untuk mendapatkan masukan yang sesuai dengan kebutuhan.

b. Tim membuat solusi alternatif yang sesuai dengan kebutuhan dan sumber daya yang tersedia, agar solusi yang ditawarkan dapat dijalankan oleh pihak masyarakat dan pemerintahan desa dan tim menyepakati solusi yang dipilih untuk diterapkan.

2. Penyuluhan dan pelatihan

Dari hasil verifikasi dengan warga Kp.Blok Benda maka diputuskan perkerasan jalan kampung dengan metode Pemasangan Paving Block jalan desa yang tindak lanjutnya dengan mengumpulkan warga untuk mengadakan pelatihan pemasangan dan penyuluhan tentang perawatan dan perbaikan kerusakan pada perkerasan paving block.

3. Implementasi

Produk yang telah dibuat diimplementasikan di Jalan Kp. Blok Benda dengan terlebih dahulu memberikan pelatihan / penyuluhan tentang penggunaan pavingisasi untuk perkerasan jalan desa.

\section{Hasil dan Pembahasan}

\section{A. Hasil}

Harapan dengan pelaksanaan Pengabdian Kepada Masyarakat (PPM) tentang Pemasangan Paving Block Jalan Desa Di Kp. Benda RT.10 RW 04 Desa Mekar Jaya Kecamatan Panongan Kabupaten Tangerang adalah sebagai berikut:

1. Kondisi Awal

Dengan belum dilaksanakan perkerasan jalan desa maka warga yang beraktivitas khususnya pada musim penghujan dengan resiko yang tinggi seriing terjadinya factor kecelakaan karena jalan yang licin.

2. Kondisi Akhir

Rencana strategis jangka pendek yaitu pengerasan jalan di realisasikan guna meningkatkan keamanan dan kenyamanan warga. Selain itu, pelaksanaan perkerasan dengan pavingisasi atau betonisasi jalan akan menyimpan air hujan sebagai tabungan di saat musim kemarau,

\section{B. Pembahasan}

Pada pembahasan kegiatan Pengabdian Kepada Masyarakat tersebut lingkup pekerjaannya yaitu :

1. Pembersihan lahan

2. Persiapan tanah untuk timbunan

3. Pembuatan lapis pasir

4. Pemasangan paving block

5. Pembuatan list beton pinggir kanan dan kirinya.

Sebelum melaksanakan pekerjaan, harus mengukur kembali semua titik elevasi dan koordinat-koordinat. Didapat hasil pengukuran panjang jalan 80 meter dan lebar jalan 2 meter. Klasifikasi pemakaian paving block untuk jalan perumahan :

$\mathrm{A}=$ paving block tebal $8 \mathrm{~cm}$.

$\mathrm{B}=$ abu batu tebal $4-5 \mathrm{~cm}$.

$\mathrm{C}=$ split $/$ sirtu/batu pecah tebal $15 \mathrm{~cm}$.

$\mathrm{D}=$ tanah dasar. 


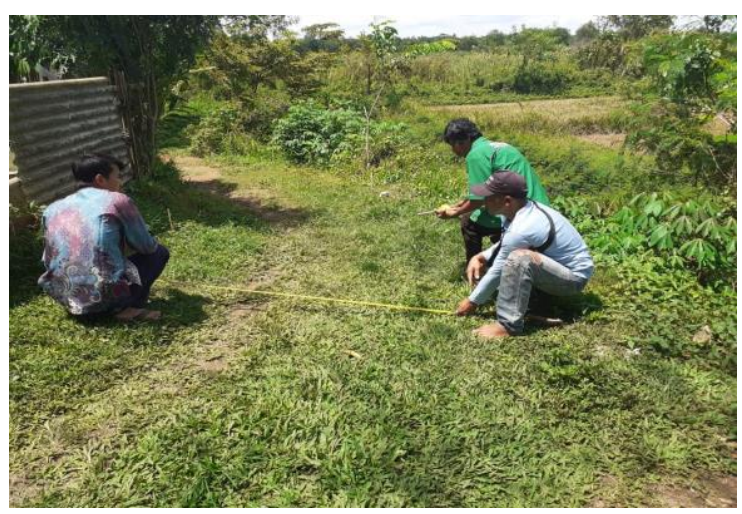

\section{Pelaksanaan}

a. Pekerjaan Timbunan Tanah

Bahan timbunan harus baik untuk pekerjaan lapisan jalan, jika dipadatkan harus dapat mencapai hasil nilai CBR minimal yang disyaratkan sebesar $6 \%$.Jika digunakan bahan timbunan yang tidak atau kurang baik dan tidak tercapai nilai CBR minimal tersebut, ini harus dibongkar dan diganti dengan bahan yang baik dan harus mengulangi pekerjaan pemadatan, jika dianggap perlu, untuk tercapainya derajat kepadatan yang diinginkan atau disyaratkan. Sebelum dipadatkan, dalamnya suatu lapisan yang akan dipadatkan tidak boleh lebih dari $20 \mathrm{~cm}$. Pemadatan harus dimulai dari tepi timbunan dengan arah longitudinal, kemudian menggeser kearah sebelah dalam (ketengah jalan).Lapisan terakhir harus diselesaikan dalam keadaan rata atau halus sampai pada suatu lapisan dengan kerataan yang diinginkan.

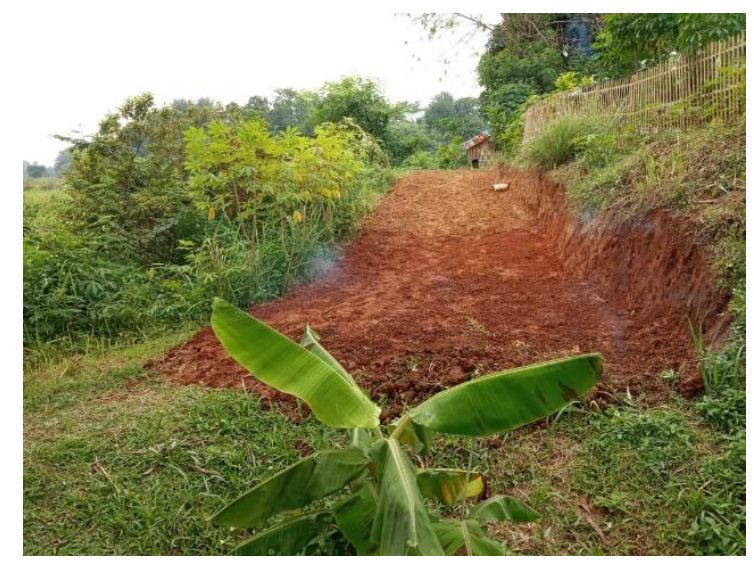

b. Pekerjaan Lapis Pasir untuk Paving Block

Pasir harus dihamparkan dengan rata diatas lapisan dasar (base course) sampai ketebalan $4 \mathrm{~cm}$ padat dengan memperhatikan kadar air dan karakteristik gradasinya. Permukaan yang dihasilkan harus rata. Bila concrete block telah selesai dipasang dan terlihat permukaan yang tidak rata maka paving block tersebut harus diangkat kembali, pasir diratakan lagi sampai diperoleh hasil yang rata. Bedding sand ini harus mempunyai kepadatan dan ketebalan yang sama sehingga pemampatan akibat pemadatan merata. Lapisan yang lepas / belum dipadatkan biasanya mempunyai ketebalan 5 sampai $15 \mathrm{~mm}$ lebih tebal dari ketebalan padat yang disyaratkan. Selama penghamparan kadar air harus uniform dan pasir yang belum dipadatkan tersebut harus dilindungi terhadap segala bentuk pemadatan dan lalu lintas, sampai paving block selesai dipasang dan bersama- 
sama. Bila ada bagian lapisan pasir yang tidak sengaja terkompaksi sebelum paving digaruk dan diratakan. Waktu penghamparan harus diperhitungkan dengan baik sehingga tidak terdapat lapisan pasir lepas yang tidak sempat ditutup dengan paving block pada hari yang sama.

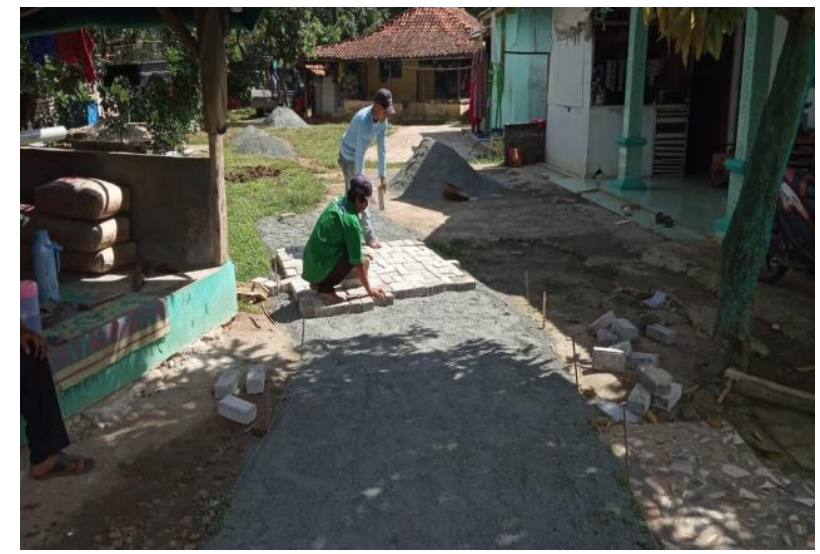

c. Pekerjaan pemasangan Paving Block

Paving Block / Grass Block harus diletakkan berhimpitan satu dengan lainnya dengan pola sesuai dengan gambar lansekap di atas bedding sand yang belum dipadatkan tapi sudah selesai diratakan. Lebar celah antar block tidak boleh lebih dari $4 \mathrm{~mm}$, celah ini harus merupakan garis lurus dan saling tegak lurus, untuk itu diperlukan pemasangan snar pada 2 arah yang saling tegak lurus untuk mengontrol letak dan ikatan antar block.

Dalam memasang block harus diusahakan agar untuk pengisian celah antara block dengan elemen-elemen lain seperti pinggiran saluran, bingkai jalan, bak kontrol dan lain-lain, dipergunakan block dengan ukuran tidak dari $25 \%$ dari ukuran utuh. Ruang antara yang masih tersisa harus diisi setelah pemadatan awal dari paving block. Untuk celah lebih besar dari $25 \mathrm{~mm}$ tetapi kurang dari $50 \mathrm{~mm}$, dipergunakan aggregate halus dengan ukuran $10 \mathrm{~mm}$ dan mortar kering untuk celah yang lebih kecil. Untuk bagian-bagian jalan yang menanjak, menurun, pemasangan block harus dilakukan dari bagian terendah kebagian yang lebih tinggi.

d. Pasir pengisi (joint filling) :

Pasir yang dipergunakan untuk mengisi celah antar block harus mempunyai gradasi sedemikian rupa sehingga $90 \%$ dari berat lolos dari tapis 1,18 mm (BS-410). Pasir ini harus cukup kering sehingga dapat mengisi celah-celah dengan baik. Bahan ini bebas dari garam dan zat-zat lain yang dapat merusak material paving block. Segera setelah pemadatan awal dan pengisian akhiran-akhiran, pasir pengisi harus segera dihamparkan dan diratakan dengan sapu sepanjang permukaan jalan atau trotoar dan dimasukkan ke dalam celah-celah antara dengan bantuan kompaktor. Celah harus benarbenar terisi oleh pasir kasar. 


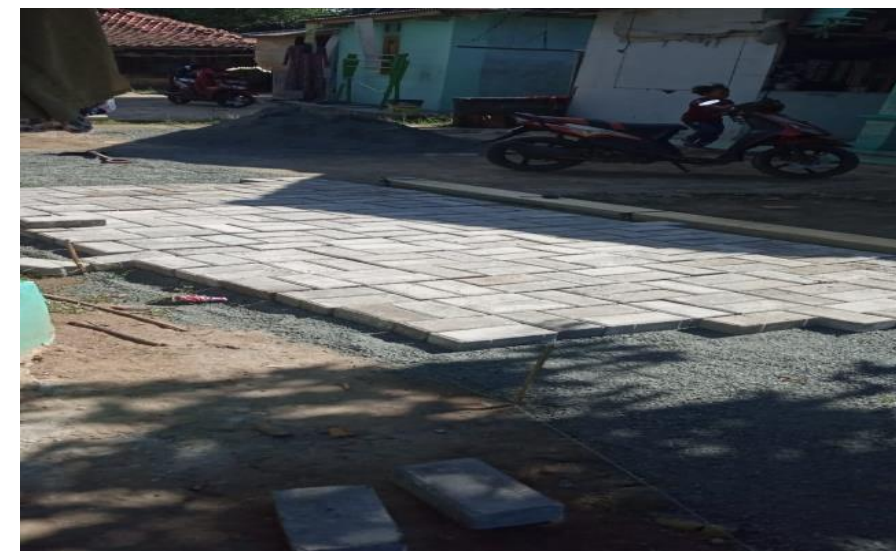

e. Pekerjaan pembuatan list beton kanan kirinya.

Sebelum pembuatan list beton kanan kirinya terlebih dulu dipasang benang untuk kelurusan dan ketebalan cor an beton yang akan dipasang dikanan kirinya jalan paving blok. Setelah terpasang benangnya dan papan kayu cor sebagai rujukan untuk pembuatan cor an beton terlebih dahulu disiapkan adukan beton yang unsurnya :

- Semen

- Pasir

- Batu split/kerikil

- Papan kayu cor

- Untuk komposisi adukannya adalah $1: 2: 3$

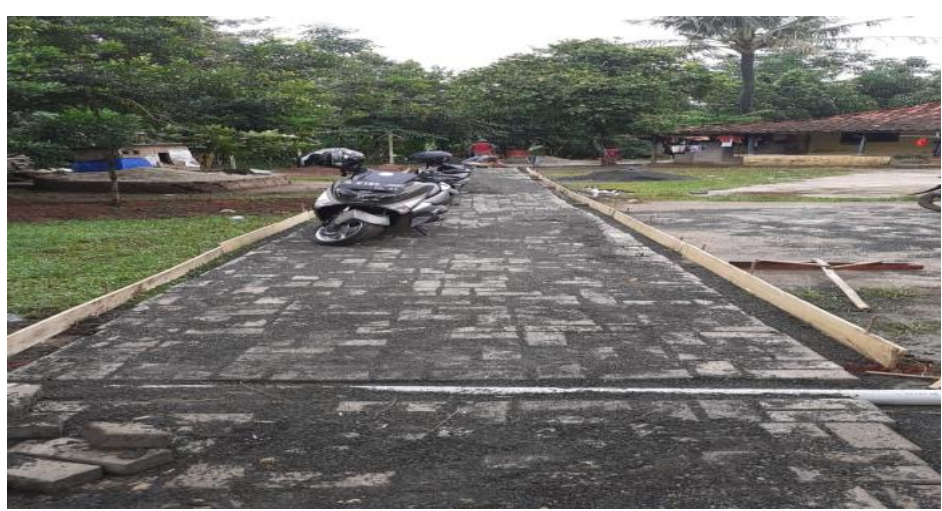

\section{Jadwal Kegiatan}

JADWAL KEGIATAN PENGABDIAN KEPADA MASYARAKAT

\begin{tabular}{|c|l|c|c|c|c|c|c|c|}
\hline \multirow{2}{*}{ No } & \multicolumn{1}{|c|}{ JENIS KEGIATAN } & \multicolumn{5}{c|}{ MINGGU Ke- } \\
\cline { 4 - 8 } & \multicolumn{1}{|c|}{$\begin{array}{l}\text { Persiapan meliputi : Persiapan ajuan proposal } \\
\text { PKM, Survey lokasi kegiatan PKM, Pengadaan } \\
\text { material kegiatan PKM, Pengadaan sarana bantu }\end{array}$} & & & & & & & \\
\hline 2 & $\begin{array}{l}\text { Pelaksanaan : Koordinasi tim PKM, Koordinasi } \\
\text { untuk pelaksanaan, Pelaksanaan kegiatan }\end{array}$ & & & & & & \\
\hline 3 & $\begin{array}{l}\text { Pelaporaan : Laporan kegiatan dalam bentuk hard } \\
\text { dan softcopy, Finish }\end{array}$ & & & & & \\
\hline
\end{tabular}




\section{Pelaksanaan Kegiatan}

Tanggal $2-12-2020$

1. Pukul 07.00 WIB, persiapan kegiatan PKM, Pengadaan material seperti : Paving blok, batu pasir,pasir pasang, split, semen dan peralatan dukung.

2. Pukul 09.00 WIB, pembukaan PKM mengenai pemasangan Paving Blok dan pemasangan lampu jalan oleh KABAAK Bpk. Sukarwoto dan kepala desa Mekar Jaya Bpk Qomarudin

3. Pelaksanaan dimulai dengan pemerataan tanah sepanjang $80 \times 2 \mathrm{~m}$

4. Setelah itu diberi pasir sepajang $80 \times 2 \mathrm{~m}$ dan dipadatkan

5. Pemasangan paving blok sepanjang $80 \times 2 \mathrm{~m}$

\section{Tanggal $3-12-2020$}

1. Pukul 08.00 WIB melanjutkan pekerjaan sampai membuat pembatas kanan kirinya dengan pengecoran sepanjang $80 \times 10 \mathrm{c} \mathrm{m}$

2. Setelah selesai baru diberikan lagi batu pasirnya untuk menutup lubang-lubang yang ada supaya terkunci pavingnya satu dengan yang lainnya sepanjang $80 \times 2 \mathrm{~m}$

\section{Kesimpulan}

Dengan melaksanakan kegiatan Pengabdian Kepada Masyarakat dalam kegiatan pemasangan paving block didesa mekar jaya diharapkan dapat membantu masyarakat dalam sarana transfortasi dan memberikan wawasan kepada masyarakat tentang perkerasan jalan serta pelatihan pemasangan dan standard jalan sesuai dengan type kendaraan yang melintas.Pelaksanaan ini dilaksanakan diwilayah sekitar PPI Curug juga sebagai partisipasi pendidikan terhadap wilayah sekitar.

\section{Daftar Pustaka}

https://arafuru.com/sipil/teknik-pembuatan-paving-block-secara-manual.html https://pabrikpavingconblock.wordpress.com/2016/04/23/cara-membuat-paving-block-endiri/ http://www.conbloc.com/post/yang-harus-diperhatikan-saat-memasang-paving-block https://marga-jaya.com/blog/cara-memasang-paving-block-conblock-yang-benar.html 